\title{
A GENETIC AND BIOCHEMICAL STUDY ON PERICARP PIGMENTS IN A CROSS BETWEEN TWO CULTIVARS OF GRAIN SORGHUM, SORGHUM BICOLOR
}

\author{
A. E. KAMBAL \\ Faculty of Agriculture, Shambat, Sudan \\ and \\ E. C. BATE-SMITH \\ Agricultural Research Council, Institute of Animal Physiology, Babraham, Cambridge, England

\section{SUMMARY} \\ In a cross between a yellow-seeded variety, Abu Taiman, and a white-seeded \\ variety, $\mathrm{CK} 60$, the $\mathrm{F}_{1}$ produced red seeds. The yellow pigment in Abu Taiman \\ was tentatively identified as erodictyol chalcone, and the red seeds, when \\ heated with mineral acid, produced the red anthocyanidins, luteolinidin and \\ apigeninidin. Pericarp colour in the cross studied, appeared to be controlled \\ by two independent factors, denoted by $r$ and $R$. While $r$ was a basic gene \\ for the synthesis of the flavonoid skeleton, gene $R$ appeared to control the \\ reduction of the flavanone (eriodictyol) into its corresponding pentahydroxy- \\ flavan (luteoforol) from which the red anthocyanidin luteolinidin, was pro- \\ duced. A pathway for the biosynthesis of luteolinidin has been suggested.
}

Received 13.v.76

\section{IntRoduction}

SoRGHUM is one of the major world cereal crops, used as human food, animal feed and a source of industrial raw materials, such as starch and other milling products. One of the factors affecting the quality of the grain, is the presence of pigments in the pericarp. In addition to their influence on the physical appearance of the grain, these pigments could impart astringency to foods (Bate-Smith and Swain, 1953) and might be adsorbed on starch during wet milling, giving objectionable colours (MacMasters and Hilbert, 1944). Information on the inheritance and nature of the pigments is of interest both intrinsically and as an aid in the improvement of grain quality. The findings of a genetic and biochemical study on the pericarp pigments in a cross between two cultivars of grain sorghum are reported herein.

\section{Materials AND Methods}

The parents of the cross were Combine Kafir 60 (CK 60), a white-seeded American variety, and a yellow-seeded type of Ethiopian origin, designated "Abu Taiman". Unlike typical grain sorghums, Abu Taiman was characterised by the occurrence of two fertile flowers per spikelet, each capable of producing a grain, and hence the Arabic name "Abu Taiman", meaning twin-seeded i.e. having two seeds per spikelet.

The cross was first made in 1970 , and the $F_{1}$ and $F_{2}$ generations were grown in 1971 and 1972, respectively, at the Faculty of Agriculture, University of Khartoum, Sudan. The pericarp pigments were identified at the Institute of Animal Physiology, Babraham, Cambridge, using standard 
procedures for anthocyanins as described and reviewed e.g. by Harborne (1967), including co-chromatography and spectrophotometric comparison with an authentic specimen.

\section{Results AND DISGUSSION}

(i) Genetic analysis

Whereas one of the parents, CK 60 had white seeds, and the other parent, Abu Taiman, had yellow seeds, the $\mathrm{F}_{1}$ plants produced red seeds. The $\mathrm{F}_{2}$ segregation (table 1 ) did not deviate significantly from a ratio of 9 red:3 yellow: 4 white, involving recessive epistasis. These results can be explained on the assumption that the parents differed in (1) a gene, $r$, necessary for the development of pigment, present in Abu Taiman but absent in CK 60; and in (2) a gene, $R$, which in the presence of $r$, produces red pigment. Since the $F_{1}$ plants produced red seeds, implying the presence

TABLE 1

Phenotypes of parents and $F_{1}$, and $F_{2}$ segregation for pericarp colour in a cross between two varieties of grain soghum

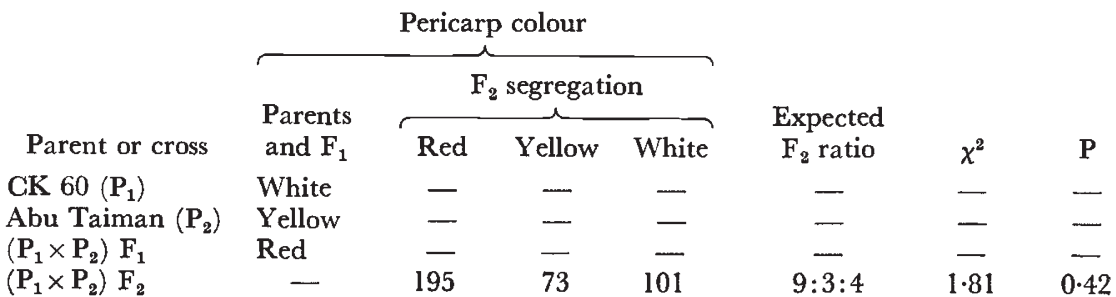

of both $Y$ and $R$, and since Abu Taiman did not carry $R$ (if it did, its seeds should have appeared red), gene $R$ must have come from CK 60 . Thus, the genotypes of the parents and their $F_{1}$ could be represented as follows: CK 60, yyRR (white); Abu Taiman, $r r_{r r}$ (yellow); $\mathrm{F}_{1}, Y_{y} R r$ (red). These findings are in accord with previous reports from India by Graham (1916) and Sakhare (1969).

(ii) Identification of the pericarp pigments in two sorghum varieties and their $F_{1}$ hybrid

Combine Kafir 60. This variety had no visible pigments, but considerable amounts of $p$-coumaric, caffeic and ferulic acids were detected.

Abu Taiman. The yellow pigment, extracted from this variety with methanolic $\mathrm{HCl}$, had 376 shifting to $449 \mathrm{~nm}$ max with $\mathrm{NaOH}$, and was possibly eriodictyol in chalcone form. The spectral values for this pigment agreed with those for other pentahydroxy chalcones listed by Harborne (1967), especially as regards the large alkali shift. When boiled with $2 \mathrm{~N} \mathrm{HCl}$ the yellow colour faded, as would be expected of the chalcone being converted to the flavanone. The yellow grains fumed with ammonia became deep orange, also as expected. Chromatography of the hydrolysate in Forestal solvent showed a bright yellow spot at $R_{F} 0.4$ becoming orange on fuming, probably unchanged chalcone. Free erodictyol, colourless but becoming reddish-brown on prolonged fuming with $\mathrm{NH}_{3}$, was present at $R_{F} 0 \cdot 8$. 
CK $60 \times$ Abu Taiman. On the chromatogram of the cross hydrolysate, the red anthocyanidin, luteolinidin, was present at $R_{F} 0 \cdot 7$, also a spot which might be apigeninidin at $R_{F} 0 \cdot 8$. There was no sign of eriodictyol or its chalcone, but unchanged luteoforol was present, as indicated by the formation of a blue-rose colour when the grains were treated with methanolic $\mathrm{H}_{2} \mathrm{SO}_{4}$ at $-15^{\circ} \mathrm{C}$.

(iii) Gene action in relation to biosynthesis of the pericarp pigments

The precise biosynthetic pathway of anthocyanin is unknown. It is accepted (Grisebach, 1968) that the first reaction in flavonoid biosynthesis is the condensation of an activated cinnamic acid with three molecules of malonyl-CoA, producing a chalcone which is in an enzyme-catalyzed

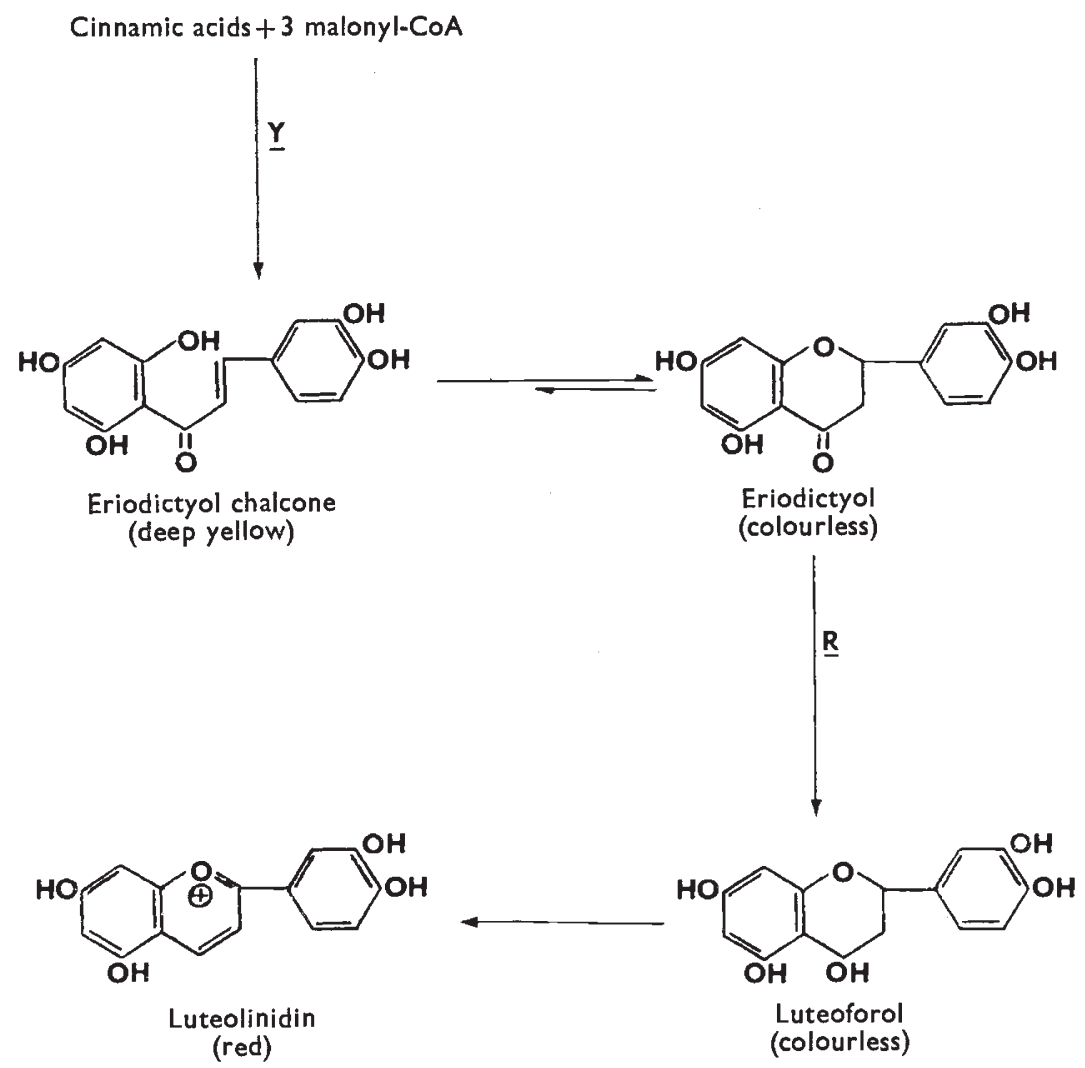

FIG. 1.-Action of genes $Y$ and $R$ in relation to the suggested biosynthetic pathway of luteolinidin in sorghum grains.

equilibrium with the corresponding flavanone. From our results, it appeared that, in the material studied, this first step was controlled by gene $r$. In Abu Taiman, where gene $r$ was present, the flavanone eriodictyol and its chalcone were produced, whereas in CK 60 , where gene $Y$ was absent, no flavonoid skeleton was produced, and the cinnamic acids, the $\mathrm{C}_{9}$ components of flavonoids, accumulated. 
Eriodictyol is related to luteoforol $\left(3^{\prime}, 4,4^{\prime}, 5,7\right.$-pentahydroxyflavan) by the reduction of the 4-carbonyl group to hydroxyl (fig. 2). Luteoforol has been prepared in the laboratory by the reduction of eriodictyol with sodium borohydride (Bate-Smith and Rasper, 1969). It is proposed that such a reduction can take place biochemically in the plant, and that, in the material studied, this reaction was under the control of gene $R$. In Abu Taiman, because gene $r$ was in the recessive condition, the biosynthesis of luteoforol was blocked, and eriodictyol and its chalcone accumulated. In CK 60, gene $R$ was present, but no luteoforol was produced, due to the absence of gene $r$ which is essential for the formation of eriodictyol, the precursor of luteoforol. In the cross CK $60 \times \mathrm{Abu}$ Taiman, both gene $Y$ and $R$ were present and luteoforol was produced.

Bate-Smith (1969) examined the luteoforol content of soghum tissues during a season's growth, and reported that, as the seeds matured, the colourless luteoforol present at the green stage was converted into the red anthocyanidin, luteolinidin. Luteoforol may be present in the unripe seed as a glucoside, and when the sugar group is removed, oxidation takes place to the anthocyanidin.

From the results of the present study, and in the light of previous findings (Grisebach, 1968) the genetic control of the biosynthesis of luteolinidin in the material studied, shown in fig. 2, can be postulated. Although, by analogy, apigeninidin could arise from apiforol in a similar manner, there was no evidence, either in the present study or in the earlier one by BateSmith (1969), that apiforol was present as the precursor of the apigeninidin found in the red seeds.

Acknowledgment.-We wish to thank Dr A. E. Abd-el-Hafeez for supplying the original sample of Abu Taiman seeds.

\section{REFERENCES}

BATE-Smith, E. C. 1969. Luteoforol (3',4,4',5,7-pentahydroxyflavan) in Sorghum vulgare L. Phytochemistry, 8, 1803-1810.

BATE-SMITH, E. C., AND RASPER, v. 1969. Tannins of grain sorghum: luteoforol (leucoluteolinidin), 3',4,4',5,7-pentahydroxyflavan. F. Food Sci., 34, 203-209.

BATE-SMITH, E. C., AND swAIN, T. 1953. Identification of leucoanthocyanins as " tannins" in foods. Chem. and Ind. (London), 377-378.

graham, R. J. D. 1916. Pollination and cross-fertilization in juar plant. Mem. Dept. Agr. India, Bot. Sec., 8, 201-216.

GRISEBACH, H. 1968. Recent investigations on the biosynthesis of flavonoids. In Recent Advances in Phytochemistry, vol. 1, ed. T. J. Mabry, R. E. Alston and V. C. Runeckles. North-Holland, Amsterdam.

harborne, J. B. 1967. Comparative Biochemistry of the Flavonoids. Academic Press, London. MACMASTERs, MAJEL M., AND HILBERT, G. 1944. Glutinous corn and sorghum starches. Ind. Eng. Chem., 36, 958-963.

SAKhare, R. s. 1969. Inheritance studies in Sorghum vulgare Pers. Plant Breeding Abst., 39, 674. 